\title{
A review of Sensorless Control in Induction Machines using HF Injection, Test
}

\section{Vectors and PWM harmonics}

\author{
R. Raute ${ }^{3)}$, C. Caruana ${ }^{1)}$, C. Spiteri Staines ${ }^{1)}$, J. Cilia ${ }^{1)}$, N. Teske ${ }^{4)}$, M. Sumner ${ }^{2)}$ and G. M. Asher ${ }^{2)}$ \\ ${ }^{1)}$ Faculty of Engineering, University of Malta, Malta. \\ ${ }^{2)}$ School of Electrical and Electronic Engineering, University of Nottingham, U.K. \\ ${ }^{3)}$ Carlo Gavazzi, Malta. \\ 4) Siemens AG Drives, Erlangen, Germany.
}

\begin{abstract}
This paper gives a review of sensorless methods developed for ac drives' operation at very low and zero speed. The sensorless drives presented in this paper use reluctance spatial anisotropy to track the mechanical rotor position, allowing the use of vector control. To extract the position information additional test signals in form of active vector pulses or continuous high frequency signals are injected into the machine. This paper also presents a technique which does not make use of additional test signals, but only components resulting from the inverter PWM pattern. Practical results show that with all reviewed methods sensorless vector control at very low and zero speed is possible. However, disturbances (eg. coming from the inverter or magnetic saturation) affect the position signal significantly and require appropriate compensation.
\end{abstract}

\section{INTRODUCTION}

Model based speed estimation in AC drives is possible at nearly all speeds, however most methods fail at low or zero speed. The reason is that their speed estimation fundamentally depends on the determination of the back-emf or the machine flux. At low speed, the back-emf decreases to an extent that noise, inaccuracies in sampled variables and inexact knowledge of the machine parameters yield relatively large estimation errors. In this respect, recent research was aimed at estimating the rotor, or airgap-flux position, using a method, which is independent of machine and inverter parameters. By tracking some form of saliency in the machine, the flux or rotor position can be estimated at zero and low speeds. Signal injection for saliency detection methods can be categorized into two types, transient and continuous.

One sensorless technique [3,14], estimates the flux angle by applying a transient test voltage and calculating the leakage inductance which varies due to the main path and leakage (slot) saturation. Another transient technique for rotor position tracking by measuring the zero-sequence voltage response to a sequence of test vectors was developed in $[6,23]$. This method was applied to a star connected induction machine (IM) The method was then developed for delta connected cage machines $[21,23,24]$, where the resulting zero-sequence current derivatives were used for rotor flux position tracking.

Methods using a continuous HF voltage injection require an observer for saliency tracking. The machine saliency will create rotor or flux position-dependent harmonics in the resulting HF stator currents which can be signal-processed to yield the required position. The observer can be configured to track magnetic flux $[7,8]$ or physical saliencies $[1,11,17,22]$.
Rotor "flux tracking" approaches yield parameterindependent flux position. These methods will give good lowspeed torque and flux control if the machine is sufficiently saturated. For sensorless position and speed control at zero and low speeds a 'trackable' rotor position dependent saliency is required. This can be the natural saliency due to rotor slotting $[6,16,17,18]$ or a designed rotor asymmetry [1,7]. Rotor position detection is successful at low loads and reduced flux. Main and leakage flux saturation will cause another saturation saliency-dependent HF harmonic in addition to that of the rotor asymmetry. The multiple saliencies so created can lead to erroneous rotor position tracking. For successful rotor position estimation, either:

(i) the rotor asymmetry needs to be designed in such a manner so as to yield a position-dependent harmonic which under all operating conditions is larger than the other HF saliency harmonics, or

(ii) the estimation method has got to be capable of taking into account multiple saliency effects.

This paper discusses various non model based rotor position tracking methods yielding sensorless speed and position control using 4 types of rotors:

Type A: $30 \mathrm{~kW}$ double cage machine with designed outer cage rotor resistance asymmetry [1]. By implementation of a sinusoidal variation over one pole pitch of the rotor outer cage resistance for a double cage IM. (Rotor resistance asymmetry was designed to be $R_{r 1 \alpha}^{r}=0.98 \Omega, R_{r 1 \beta}^{r}=9.98 \Omega$.)

Type B: $30 \mathrm{~kW}$ machines exhibiting rotor slotting. These machines are generally open or semi-closed slot and the optimum rotor slot number can be selected from the criteria in [12]. (Type B machine uses a near-standard industrial rotor with $N_{r}=56$ unskewed rotor slots [17]).

Type C: Standard $5.5 \mathrm{~kW}$ machines exhibiting very low rotor slotting. The rotor is a skewed squirrel cage design with semi opened rotor slots ( 2 pole pairs, 32 rotor slots, 36 stator sloths).

The paper shall also look at sensorless algorithms with additional signal injection in sections II and III and techniques without additional signal injection in section IV. 


\section{CONTINUOUS HF INJECTION FOR TRACKING ROTOR POSITION SALIENCIES}

The control structure of Fig. 1 shows the system block diagram used for sensorless speed or position control. For the case of the continuous HF injection technique, the HF carrier voltage injected is :

$$
v_{s \alpha \beta_{-} c}^{s}(t)=V_{c} e^{j \omega_{c} t}
$$

In general the resulting $\mathrm{HF}$ stator currents including saturation-dependent harmonics will be :

$$
\underline{i}_{s \alpha \beta_{-} c}^{s}(t)=I_{1} e^{j\left(\omega_{c} t+\phi_{1}\right)}+I_{2} e^{j\left(n \theta_{r}-\omega_{c} t-\phi_{2}\right)}+I_{3} e^{j\left(2 \theta_{e}-\omega_{c} t-\phi_{3}\right)}
$$

Where $\mathrm{n}$ is 2 for Type A machine whilst for machines tracking rotor slot frequencies it is given by $N r / p p$, where $N r$ is the number of rotor slots and $p p$ is the pole pair number. $\left(\phi_{1,2,3}\right.$ are arbitrary phase angles).

On applying HF injection to Type A machine, using the scheme shown in Fig. 2, from (2) (following filtering, $I_{3}$ can be assumed 0) it can be shown [10] that a form of linear error is obtained:

$$
\xi_{f}=I_{2} \sin \left(2\left(\theta_{r}-\hat{\theta}_{r}\right)-\phi_{2}\right)
$$

For this error to go to zero, we can write:

$2\left(\theta_{r}-\hat{\theta}_{r}\right)-\phi_{2} \approx 0$ and, $\hat{\theta}_{r} \approx \theta_{r}-\frac{\phi_{2}}{2}$

Type A machine was operated using an indirect rotor flux orientation (IRFO) scheme for speed or position control. A HF voltage injection of about $300 \mathrm{~Hz}$ was used. The resulting HF current magnitude was about $7 \%$ of the rated main excitation current. Fig.3. shows the resulting stator HF current obtained under sensored speed control with a demand of $600 \mathrm{rpm}$. Fig. 4. shows the step response to a position demand of 360 mechanical degrees at $50 \%$ rated load.

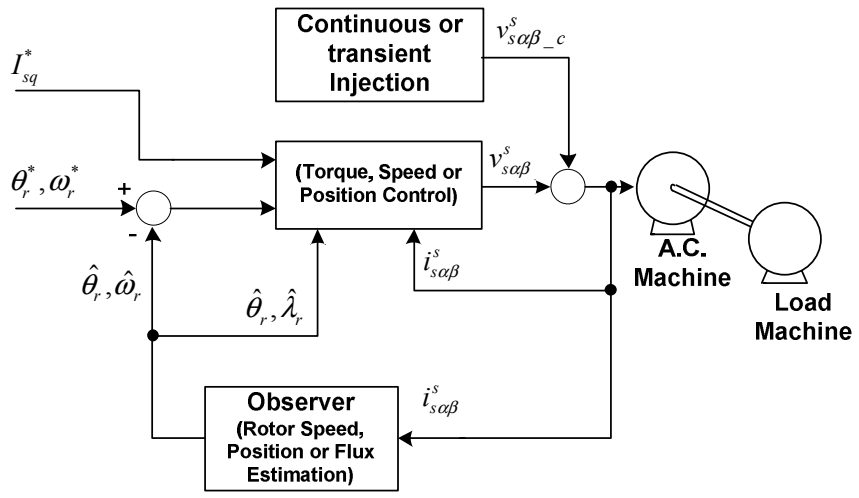

Fig. 1. Sensorless Control System.

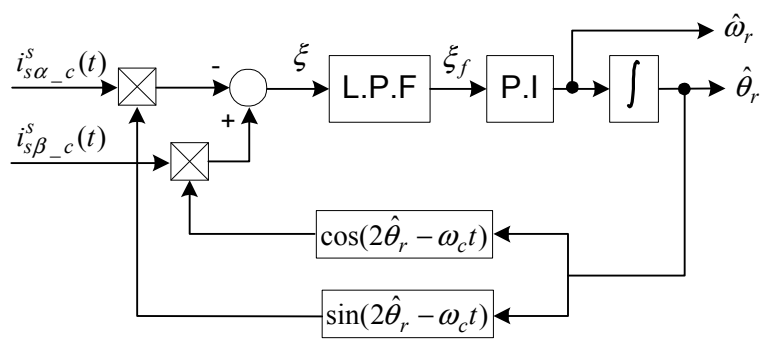

Fig. 2. A closed-loop position and velocity PLL using phase detector based on the heterodyning technique.

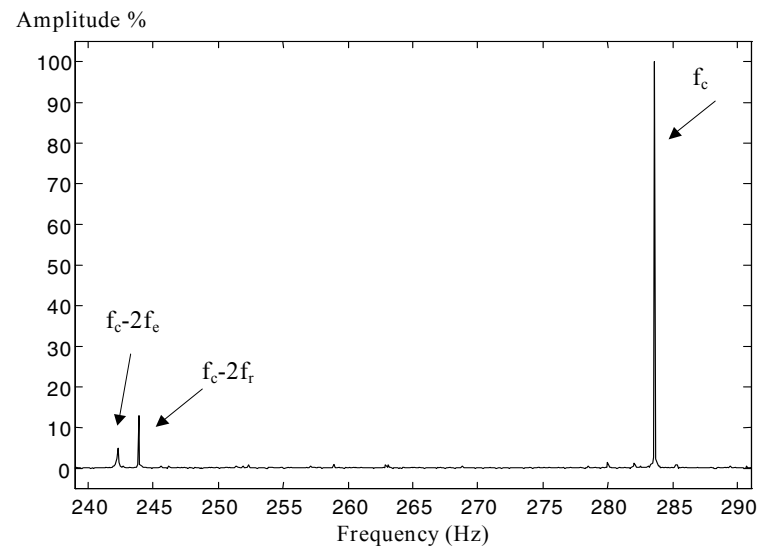

Fig. 3. HF Current Spectrum at $600 \mathrm{rpm}$ and $50 \%$ load.

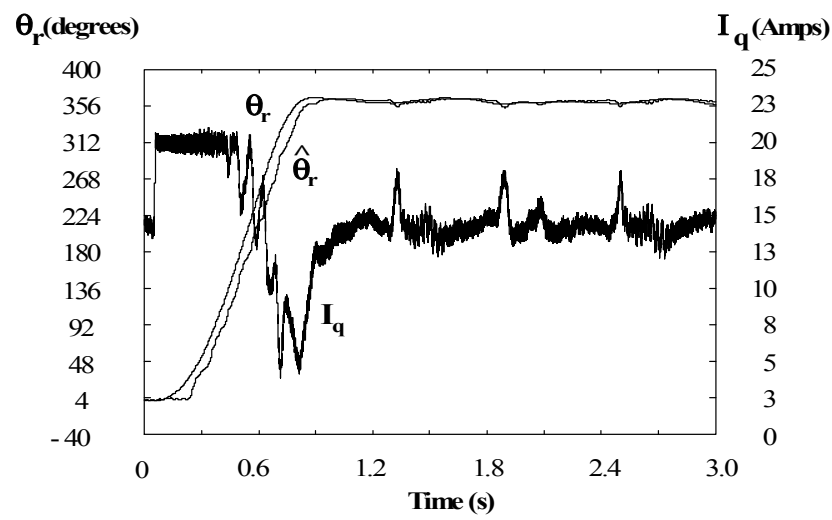

Fig. 4. Sensorless position response to a transient demand of $360^{\circ}(50 \%$ rated load.) Suppression of the Saturation Harmonics

The system (Fig. 4) becomes susceptible to a low frequency oscillation which worsens once the load is increased beyond $50 \%$. The oscillations are due to the saturation-induced HF harmonics $\left(f_{c}-2 f_{e}\right)$. A possible solution to suppress the deteriorating effect of the saturation-dependent HF harmonics (at $2 f_{e}$ and multiples) is to implement a compensation scheme such as the structure of Fig. 5. If only one saliency is present, the output negative sequence signal $i_{s d q_{-} c}^{s}$ will then contain the sin and cos of the position angle. In practice however there will be additional parasitic saliencies together with the dominant saliency. The Harmonic Compensation (HC) technique [11] can be applied to remove distorting or unwanted harmonics. It has been shown to be effective if only a small number of harmonics have to be suppressed. Commissioning prior to operation needs to be carried out to determine the 'un-desired' harmonics (magnitude $i_{C 1}$, phase $\varphi_{C 1}$ ) as a function of the operating point $\left(i_{s d}, i_{s q}\right)$ and the stator current angle $\theta_{e}$. 


$$
\begin{gathered}
\hat{i}_{C 1}=f\left(i_{s d}, i_{s q}\right) \\
\hat{\theta}_{C 1}=f\left(i_{s d}, i_{s q}, \theta_{e}\right) \approx 2 \theta_{e}+\hat{\varphi}_{C 1}
\end{gathered}
$$

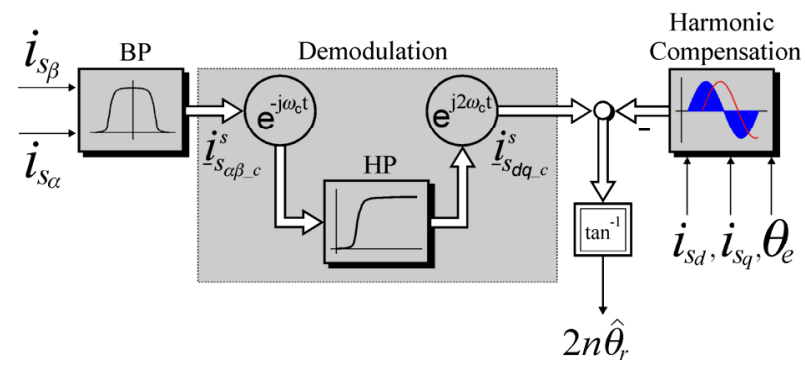

Fig. 5. Structure for demodulation and transformation of negative sequence harmonics.

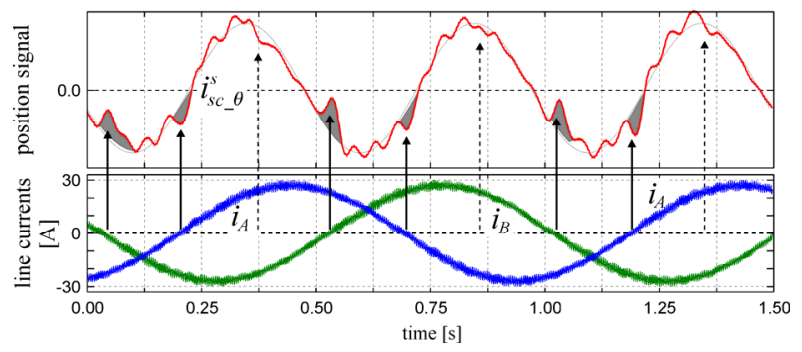

Fig. 6. Top: Discrete distortion of position signal $i_{s c \_}^{s}$ after HC, for asymmetric machine (Type A, harmonic at $2 f_{r}$ ). Bottom: line currents.

\section{A. Suppression of the Inverter Modulation Harmonics}

If the available rotor saliency is small, the inverter nonlinearity can introduce significant distortions in the HF signals. Fig. 6. shows the distortion (grey areas) in the demodulated negative sequence signal in Type A machine driven from a $45 \mathrm{~kW}$ inverter after applying $\mathrm{HC}$ in the time-domain. The distortion is most pronounced at the time of the zero crossing of the line currents. Fig. 7. shows the frequency spectrum of the position signal for the Type B machine. The invertermodulation harmonics appear at the same frequencies of the saturation harmonics and are multiples of twice the excitation frequency $\left(2 f_{e}\right)$ and depend on the operating conditions. The shorter the zero crossing, the smaller the distortion. If a larger dead-time cannot be avoided, a dead-time compensation scheme may be implemented.

A second possibility for improving the position estimate is to implement a compensation strategy that suppresses the HF inverter modulation [18]. Space Modulation Profiling (SMP) was developed and carries out real-time compensation using a pre-determined envelope of the 'un-desired' harmonic distortion signals (multiples of the fundamental frequency). The harmonics due to the saturation saliency and the inverter distortions are removed from the demodulated HF currents using a pre-loaded profile for the direct position signal axis and a similar profile for the quadrature axis. The profile is recorded for rated flux and different load over the stator current angle.

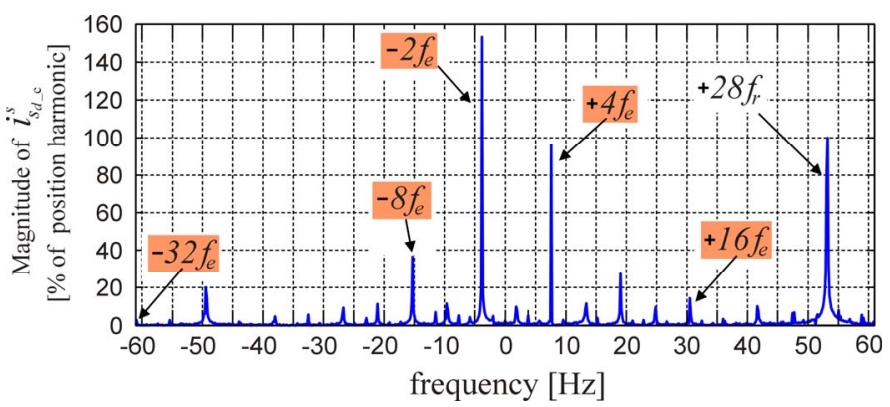

Fig. 7. Spectrum of the demodulated position signal $i_{s d_{-} c}^{s}$ for symmetric machine (Type B) with slotting saliency harmonic at $28 f_{r}$.

\section{B. Results of HC and SMP Techniques}

The drive was connected as shown in Fig. 1 together with the rotor position estimator of Fig. 5, where either HC or SMP can be used. The estimated rotor position was used for field orientation and serves as the feedback to the position controller. The position controller is a lead controller. The rotor position tracking and sensorless position control was tested using different induction machines under full flux and all loads. The first experimental results are taken using a delta-connected Type A induction machine. The saturation saliency is suppressed using the $\mathrm{HC}$ technique. The inverter modulation suppression (SMP) was not used.

Fig. 8. shows the rotor position and the vector currents $i_{s d}$ and $i_{s q}$ during a fast position transient of the sensorless drive when the rotor position is changed by 360 degrees mechanical, at $80 \%$ rated load and rated flux. The position change is performed in less than 0.7 seconds. The upper plot of Fig. 8 shows the real and estimated rotor position. During this experiment, the $i_{s q}$ current limit was set to $36 \mathrm{~A}$ to deliver the high load torque and the additional transient torque.
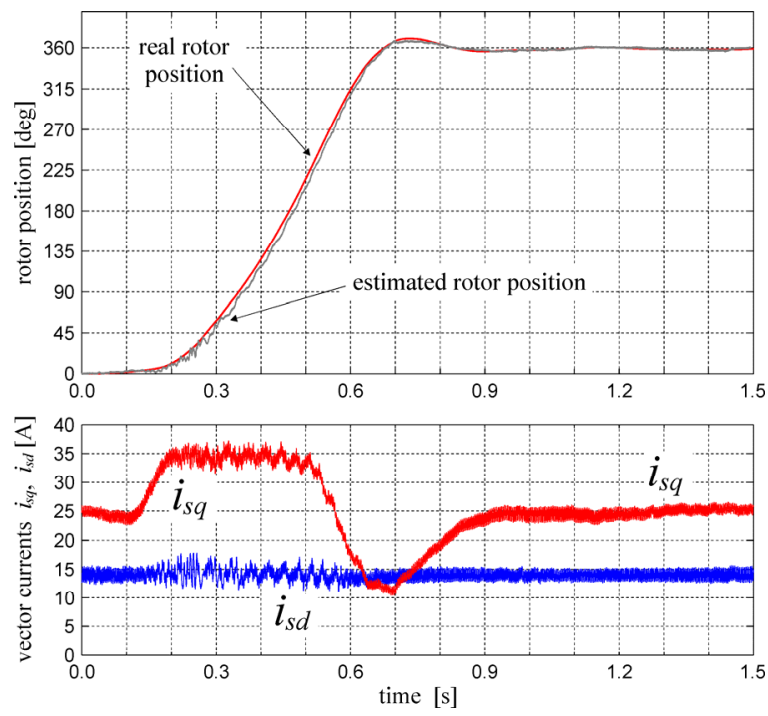

Fig. 8. Sensorless position change by one revolution for asymmetric machine. Top: real and estimated rotor position. Bottom: vector currents. 

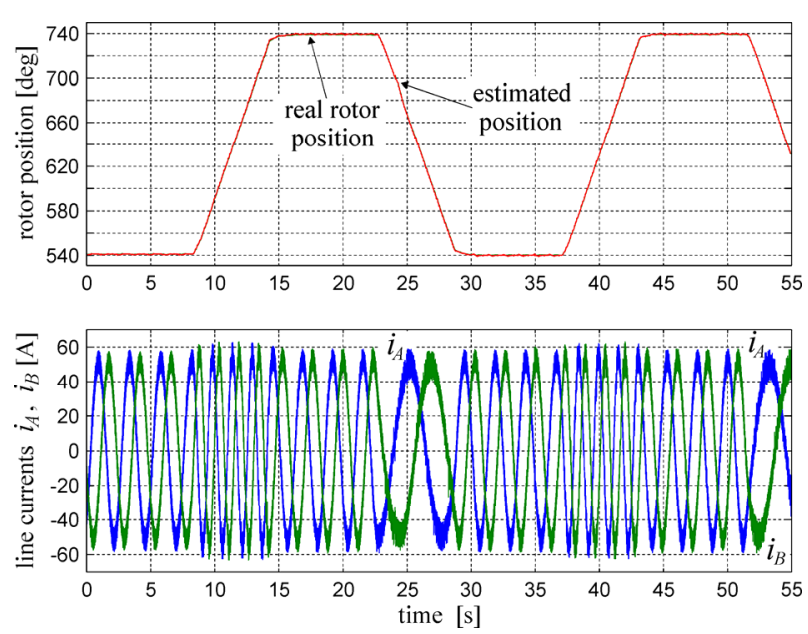

Fig. 9. Sensorless position control using the symmetric machine under $65 \%$ rated load. Top: reference, real and estimated rotor position. Bottom: Stator line currents $i_{A}$ and $i_{B}$.

The second machine tested was the delta-connected Type B machine. The saliency due to the rotor slots was used for position estimation. SMP was used to suppress saturation and inverter modulation to make sensorless control possible. Fig. 9. shows a sequence of slow position changes by 200 degrees mechanical and position holding for the fully fluxed machine. The load is constant and at $65 \%$ rated. During a position change, the rotor moves at a speed of 5.5rpm. The difference between real and estimated position has an error with a standard deviation of less than 0.45 degrees mechanical for all operating conditions.

\section{Zero SEQuence CurRent Derivative Method}

The Zero Sequence Current Derivative (ZSCD) method of position estimation involves applying voltage test vectors corresponding to six non-zero switching states of a voltage source inverter (VSI). The test vectors, which are defined in Figure 10, are of short duration (12-15 $\mu$ s) and are applied in between the fundamental PWM generation. The vectors are applied in equal and opposite pairs $\left(V_{1}, V_{4}\right),\left(V_{3}, V_{6}\right)$ and $\left(V_{5}, V_{2}\right)$ and will have no effect on the fundamental excitation of the machine [21]. For every test voltage vector corresponding currents will flow in each phase of the machine, including the zero sequence component. The derivative of the latter is measured by a single non-integrating Rogowski coil.

For an IM, it can be shown that the stator leakage inductance, $l_{\sigma}$ varies sinusoidally with respect to both the flux and rotor angle under the effects of main-flux/tooth saturation and rotor slotting respectively. Considering both effects, we have:

$$
\begin{aligned}
& l_{s \sigma_{-} x}=l_{s \sigma}-\Delta l_{s \sigma_{-} s a t} \cos \left(2 \omega_{e} t-k \cdot 2 \pi / 3\right) \\
& -\Delta l_{s \sigma_{-} R S} \cos \left(n \omega_{r} t-k \cdot 2 \pi / 3+\phi\right)
\end{aligned}
$$

where phase ' $\mathrm{x}$ ' corresponds to phase $\mathrm{a}, \mathrm{c}, \mathrm{b}$ for $\mathrm{k}=0,1,2$ respectively. $l_{s \sigma}$ is the average inductance per phase and $\Delta l_{s \sigma}$ sat and $\Delta l_{s \sigma R S}$ are the change in leakage inductance caused by saturation and rotor slotting respectively.
To detect the change in inductance, the test voltage vector pairs, $\left(V_{1}, V_{4}\right),\left(V_{3}, V_{6}\right)$ and $\left(V_{5}, V_{2}\right)$ corresponding to Fig. 10 are applied over successive PWM cycles. For a delta-connected machine the ZSC is given by:

$$
i_{s_{-} 0}=i_{s_{-} a b}+i_{s_{-} b c}+i_{s_{-} c a}
$$

Sampling the test vector pair gives a three phase system of "position" signals:

$$
\begin{aligned}
& p_{a}=\frac{d i_{s_{-} 0}^{1}}{d t} \text { or } \frac{d i_{s_{-} 0}^{4}}{d t} \quad p_{b}=\frac{d i_{s_{-} 0}^{3}}{d t} \text { or } \frac{d i_{s_{-} 0}^{6}}{d t} \\
& p_{c}=\frac{d i_{s_{-} 0}^{5}}{d t} \text { or } \frac{d i_{s_{-} 0}^{2}}{d t}
\end{aligned}
$$

where:

$$
\begin{aligned}
& p_{a}=\Delta l_{s \sigma_{-} s a t} \cos \left(2 \omega_{e} t-4 \pi / 3\right)+\Delta l_{s \sigma_{-} R S} \cos \left(n \omega_{r} t-4 \pi / 3+\phi\right) \\
& p_{b}=\Delta l_{s \sigma_{-} s a t} \cos \left(2 \omega_{e} t-2 \pi / 3\right)+\Delta l_{s \sigma_{-} R S} \cos \left(n \omega_{r} t-2 \pi / 3+\phi\right) \\
& p_{c}=\Delta l_{s \sigma_{-} s a t} \cos \left(2 \omega_{e} t\right)+\Delta l_{s \sigma_{-} R S} \cos \left(n \omega_{r} t+\phi\right)
\end{aligned}
$$

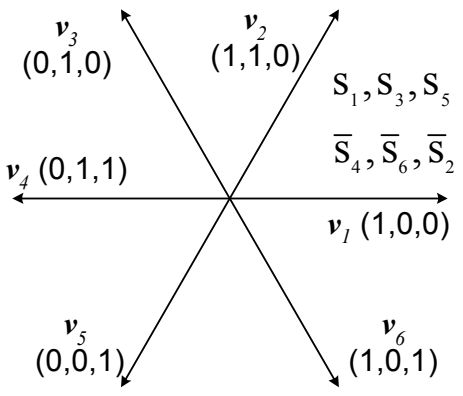

Fig. 10. S1,S2,S3 correspond to the switching state of leg 1,2,3 of an inverter.

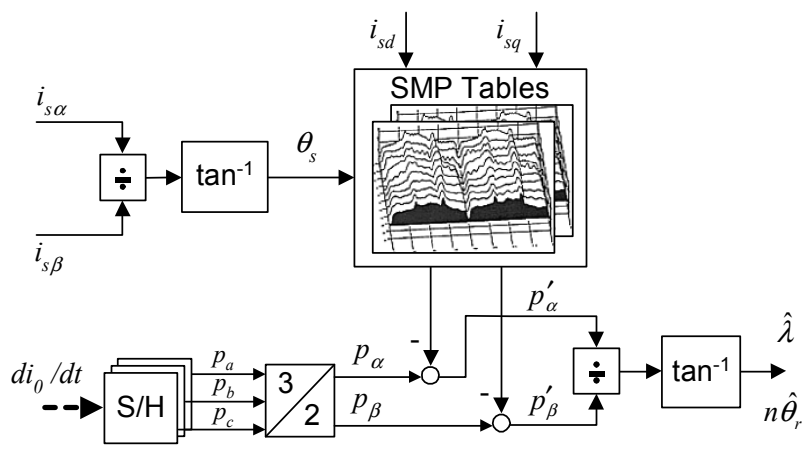

Fig. 11. Basic ZSCD Flux/Rotor Position Estimation System

Equation (9) represents a three phase system of flux and rotor angle dependent signals which can be transformed to a 2phase system $\left(p_{o}, p_{\beta}\right)$. The first terms, $\left(\Delta l_{s \sigma_{-} s a t}\right)$, are dependent on machine saturation whilst the second terms, $\left(\Delta l_{s \sigma_{-} R S}\right)$ are dependent on rotor slotting and contain the 'rotor position dependent' information. It is noted that (9) is ideal; in practice harmonics of the saturation component $2 k \omega_{e}, k=2,3, \ldots$, will exist arising from non-linear converter effects, saturation space 
harmonics [18] and high order terms arising from the binomial expansion used in the derivation of (6).

\section{A. Harmonic Separation}

Since the separation of the different harmonic components of (9) cannot be done using real-time filtering a SMP-based method was used to obtain clean positions signals for rotor position estimation. Fig. 11 shows the configuration of the SMP memory compensation to obtain clean position signals. The compensation terms are referenced by the actual torque current $\left(i_{q}\right)$, the field current $\left(i_{d}\right)$ and the stator current vector angle $\left(\theta_{s}\right)$. After correction of the position dependent signals $\left(p_{\alpha}\right.$ and $\left.p_{\beta}\right)$, are used to determine a rotor position estimate:

$$
n \hat{\vartheta}_{r}=\tan ^{-1}\left(\frac{p_{\beta}^{\prime}}{p_{\alpha}^{\prime}}\right)
$$

\section{B. Sensorless control using the ZSCD method}

In the following experimental results, Type B machine was operated under sensorless speed control where the estimated rotor position angle from (10) was directly used for the dq axis transformations using an IRFO control structure. A SMP table for this machine was derived to compensate for corrupting harmonics. A low pass filter of $8 \mathrm{~Hz}$ was applied to the differentiated rotor position estimate to provide the speed feedback. The inverter available at the time allowed a maximum loading of $40 \%$ rated load for Type B motor.
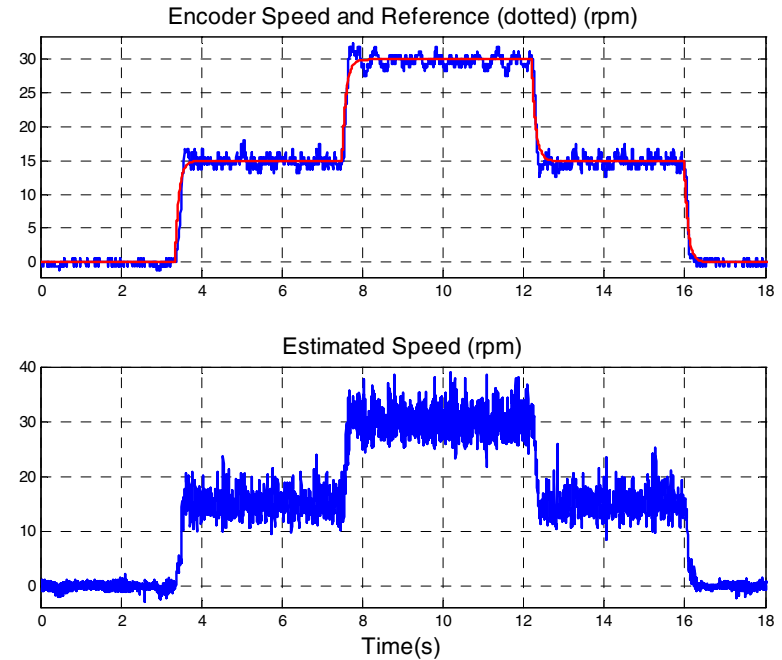

Fig. 12. Speed Sensorless control for $0-15-30$ rpm step demands at $40 \%$ rated load. Top: Encoder speed \& Ref. (rpm). Bottom: Estimated speed (rpm).

Fig. 12 and 13 show the response of sensorless speed control to step and ramp demands of zero and low speed operation. Fig. 14 shows sensorless speed operation (over 25 seconds) during a negative speed demand of $8.5 \mathrm{rpm}$ and $40 \%$ rated load. During the negative speed, the fundamental frequency falls down to zero (Fig. 14, middle waveform shows that line currents are DC).
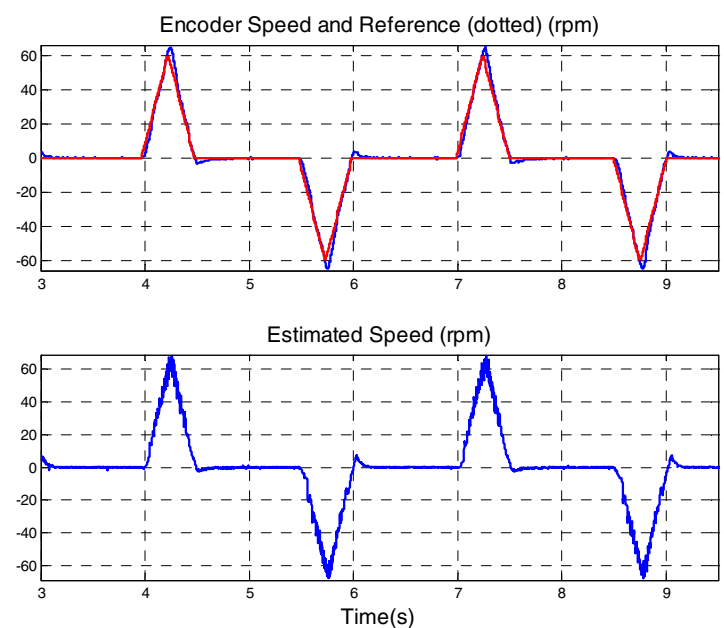

Fig. 13. Speed Sensorless control for $60 \mathrm{rpm}$ ramp demand..Top: Sensorless operation with Positive and Negative Speed Ramp Demand (acceleration: 250rpm /s). Bottom : Estimated Speed.
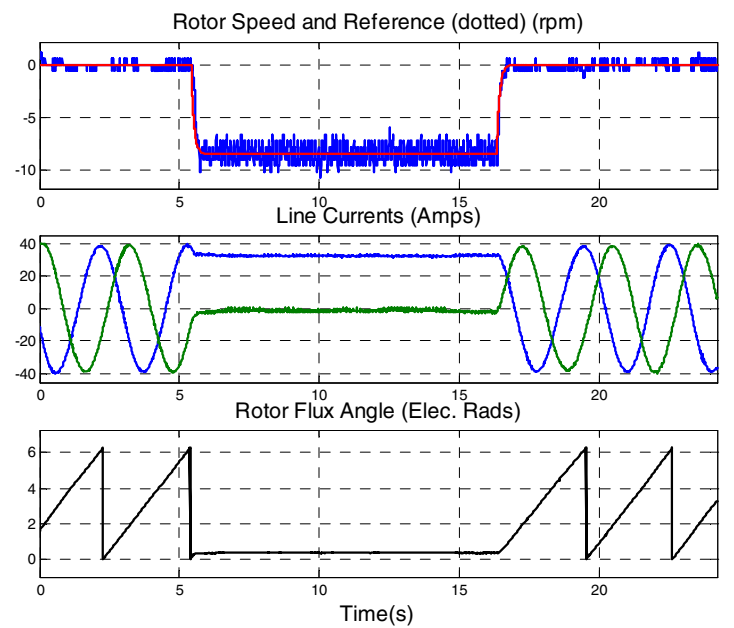

Fig. 14. Sensorless Speed Control at $-8.5 \mathrm{rpm}$ with $40 \%$ load application reducing fundamental frequency to $0 \mathrm{~Hz}$. Top: Encoder Speed \& Ref. (rpm). Middle: Line currents (Amps). Bottom: Rotor Flux Angle (elec. rads).

\section{USING PWM HARMONICS FOR ROTOR BAR SLOTTING DETECTION OF INDUCTION MACHINES}

\section{A. Use of PWM harmonica for saliency detection}

In this method, the PWM harmonics are used as an "injected" HF excitation signal [26]. It was found that at low speed the $2^{\text {nd }}$ PWM harmonic has the largest amplitude [26]. Therefore only the $2^{\text {nd }}$ PWM harmonic is used in the sensorless algorithm. All variables referred to this PWM harmonic are further denoted as PWM2. The $2^{\text {nd }}$ PWM carrier harmonic can be described as a pulsating vector, rotating approximately synchronously with the fundamental voltage vector in the stator fixed $\alpha \beta$ frame [26], as shown in (11). 


$$
\begin{aligned}
\underline{v}_{P W M 2 \alpha \beta}=\frac{2}{3} \frac{V_{D C}}{\pi}( & \sin \left(\pi m_{A}\right)+\sin \left(\pi m_{B}\right) e^{j \frac{2}{3} \pi} \\
& \left.+\sin \left(\pi m_{C}\right) e^{j-\pi}\right) \cos \left(2 \omega_{P W M} t\right)
\end{aligned}
$$

The resulting current PWM2 carrier harmonic together with the "injected" HF can be used for detecting the impedance inside the machine, similar to HF pulsating injection drives. However as the HF pulsating vector amplitude and phase are now determined by the fundamental operation, a novel position observer is required.

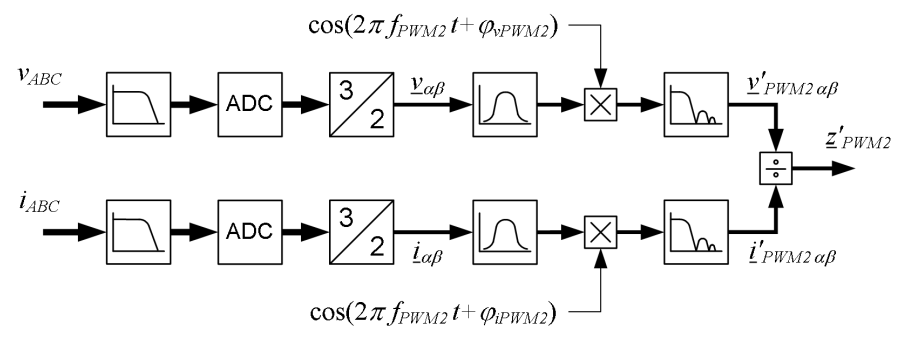

Fig. 15. Block diagram of PWM2 signal demodulation

Fig. 15 shows a block diagram of the implemented signal processing. The measured three phase voltages and currents are directly combined in the time domain to the resulting stator voltage and current vector $\left(\underline{v}_{\alpha \beta}, \underline{i}_{\alpha \beta}\right)$. The $\alpha \beta$ components of the vectors are band pass filtered. The filter's centre frequency is set to twice the PWM switching frequency. The band pass filtered signals are further demodulated by a heterodyning technique. The HF carrier frequency component is removed by a discrete average filter. As result only the amplitude modulation signals $\underline{v}_{P W M 2}^{\prime}$ and $\underline{i}_{P W M 2}^{\prime}$ of the $f_{P W M 2}$ voltage and current signals are derived. An equivalent impedance vector $\underline{z}^{\prime}{ }_{P W M 2}$ can be defined based on the demodulated voltage and current PWM carrier harmonic vectors $\underline{v}_{P W M 2}^{\prime}$ and $\underline{i}_{P W M 2}^{\prime}(12)$. The ratio between $\underline{v}_{P W M 2}^{\prime}$ and $\underline{i}_{P W M 2}^{\prime}$ takes the uncontrolled variation in the "injected" HF excitation into account. The complex vector division can be calculated in any reference frame. The result will be only affected by the phase and magnitude difference of the two vectors. The final HF equivalent impedance vector $\underline{z}_{P W M 2}^{\prime}$ is calculated by the complex vector division directly in the $\alpha \beta$ frame.

$$
\underline{z}_{P W M 2}^{\prime}=\frac{\underline{v}_{P W M 2}^{\prime}}{\underline{i}_{P W M 2}^{\prime}}
$$

The focus of this work is to detect the asynchronous modulation due to the conductor bars embedded in the rotor iron package of the machine. It is assumed that the rotor bars cause a circular equivalent impedance modulation with the amplitude $\Delta Z_{R B}^{\prime}$. The angle $\theta_{R B}$ is the rotor bar position within one rotor bar period, which is the distance between 2 adjacent rotor bars. The resulting voltage equation system for the demodulated PWM2 variables is shown by (13).
$\left[\begin{array}{c}v_{P W M 2 \alpha}^{\prime} \\ v_{P W M 2}^{\prime}\end{array}\right]=\left[\begin{array}{cc}Z^{\prime}-\Delta Z_{R B}^{\prime} \cos \left(\theta_{R B}\right) & \Delta Z_{R B}^{\prime} \sin \left(\theta_{R B}\right) \\ \Delta Z_{R B}^{\prime} \sin \left(\theta_{R B}\right) & Z^{\prime}+\Delta Z_{R B}^{\prime} \cos \left(\theta_{R B}\right)\end{array}\right] \cdot\left[\begin{array}{l}i_{P W M 2 \alpha}^{\prime} \\ i_{P W M 2}^{\prime}\end{array}\right]$

The result of the complex vector division (12) is stated by (14) which shows that an equivalent impedance vector with an offset $Z^{\prime}$ and a circular modulation with the radius $\Delta Z_{R B}^{\prime}$ rotating backwards with $\theta_{R B}+2 \angle \underline{i}^{\prime}{ }_{P W M 2} \alpha \beta$ occurs.

$$
\begin{aligned}
{\underline{z^{\prime}}}^{\prime}{ }_{\text {WM } 2}= & Z^{\prime}-\Delta Z_{R B}^{\prime} \cos \left(\theta_{R B}+2 \angle i_{P W M 2 \alpha \beta}^{\prime}\right) \\
& +j \Delta Z_{R B}^{\prime} \sin \left(\theta_{R B}+2 \angle i_{P W M 2 \alpha \beta}^{\prime}\right)
\end{aligned}
$$

After compensating for the offset, the additional $2 \angle \underline{i}_{P W M 2}^{\prime} \alpha \beta$ phase modulation can be easily removed since the HF current vector position $\angle \underline{i}^{\prime}{ }_{P W M 2} \alpha \beta$ is directly known.

\section{B. Compensation for additional modulation effects}

In the theoretical explanation it is assumed that the average machine equivalent impedance $Z$ ' and the modulation effects are superimposed as stated in (15).

$$
\underline{z}_{P W M 2}^{\prime}=Z^{\prime}+\Delta \underline{z}_{P W M 2 S a t}^{\prime}+\Delta \underline{z}_{P W M 2 R B}^{\prime}+\Delta \underline{z}_{P W M 2 I n v}^{\prime}
$$

In the used (Type C) machine the measured rotor bar modulation $\Delta Z^{\prime}{ }_{R B}$ is very low (1 to $1.5 \%$ of the offset value $Z$ ') due to the rotor construction and particularly the skewing. The saturation modulation $\Delta \underline{z}_{P W M 2 S a t}^{\prime}$ is up to $4 \%$ of $Z$ '. It was observed that a further modulation occurs with each current commutation sector. This effect is assumed to be due to inverter non-linearity, caused by the dead time during the switching between the two IGBT's per phase leg and current clamping effects [26]. The amplitude of this inverter modulation $\triangle z^{\prime}{ }_{P W M 2 I n v}$ is in the range of about 2 to $3 \%$ of $Z$, and is actually higher than the slotting effect to be tracked. Therefore the decoupling of the desired signal for the rotor position estimation from the other distorting effects is a critical task. In this work a basic look up table (LUT) compensation scheme is implemented to extract only the desired rotor bar modulation. As shown in [26], the saturation modulation depends on the imposed stator current vector and the relative position $\angle \underline{i}^{\prime}{ }_{P W M 2}$. In the regarded operation $i_{d}$ is kept constant and thus the total machine current amplitude depends directly on the torque producing current component $i_{q}$. Since the current controller has a fast dynamic response, $i_{q}{ }^{*}$ is used as a reference for the LUT for noise reduction. A further compensation dimension $\angle \underline{i}^{\prime}{ }_{P W M 2}-\angle \underline{i}$ is used as a second reference for the LUT. For the compensation of the inverter non-linearity effect $\angle \underline{i}_{\alpha \beta}$ is used as the third LUT dimension. The final implemented LUT contains the values of $\underline{z}_{P W M 2 ~ L U T}$ (16) addressed by the three reference dimensions.

$$
\underline{z}_{P W M 2 L U T}^{\prime}\left(i_{q}, \angle i_{\alpha \beta}, \angle i_{P W M 2}^{\prime}-\angle i\right)=Z^{\prime}+\Delta \underline{z}_{P W M 2 S a t}^{\prime}+\Delta \underline{z}_{P W M 2 I n v}^{\prime}
$$


The look up table was created using a special commissioning test. The drive is operated in fully sensored vector control mode over the whole of the required operating range required for the proposed sensorless algorithm i.e variable speed and $i_{q}$. The $i_{q}$ current, the stator current angle $\angle \underline{i}_{\alpha \beta}$ and the angle $\angle \underline{i}^{\prime}{ }_{P W M 2}-\angle \underline{i}$ are acquired together with the measured equivalent impedance vector $\underline{z}_{P W M 2}$. Therefore the $\underline{z}_{P W M 2}$ modulation is measured including the rotor bar, saturation and inverter non-linearity modulation for the entire operation range. The measured data is processed off-line according to the measured $i_{q}, \angle \underline{i}_{\alpha \beta}$ and $\angle \underline{i}^{\prime}{ }_{P W M 2}-\angle \underline{i}$ parameters. Data points with same $i_{q}, \angle \underline{i}_{\alpha \beta}, \angle \underline{i}_{P W M 2}{ }^{\prime} \angle \underline{i}$ references are averaged. Since the rotor bar modulation is asynchronous to the measured $i_{q}, \angle \underline{i}_{\alpha \beta}, \angle \underline{i}^{\prime}{ }^{\prime}{ }_{W M 2}-\angle \underline{i}$ parameters and the data was collected over a finite time duration, it is assumed that the rotor bar modulation is removed due to averaging of several samples per $i_{q}, \angle \underline{i}_{\alpha \beta}, \angle \underline{i}^{\prime}{ }_{P W M 2}-\angle \underline{i}$ reference. Thus a $\underline{z}^{\prime}{ }_{P W M 2}{ }_{L U T}$ modulation profile is generated which does not include the rotor bar modulation. Figs. 16 and 17 show the real and imaginary part of the measured $\underline{z}^{\text {' }}{ }^{\prime}{ }_{W M}$ LUT profile dependent on $\angle \underline{i}_{\alpha \beta}$ and $\angle \underline{i}^{\prime}{ }_{P W M 2}-\angle \underline{i}$ for the rated current. The parameter range is discretised by $2^{\circ}$ ele for both reference parameters. The flat sections in the figures show conditions that did not occur during operation. The $\angle \underline{i}^{\prime}{ }_{P W M 2}-\angle \underline{i}$ range is limited due to the fundamental operation of the machine and therefore the saliency function is only detected in a small section of the $360^{\circ}$ ele range. Also during sensorless operation only points in the detected section can occur and thus the knowledge of this compensation profile is sufficient.

In the shown equivalent impedance profile of $\underline{z}_{P W M 2 L U T}$ one can notice the parameter dependency of $\angle \underline{i}_{\alpha \beta}$ and $\angle \underline{i}^{\prime}{ }_{P W M 2}-\angle \underline{i}$. It can be seen that the real part offset $Z$ ' is about $190 \mathrm{~V} / \mathrm{A}$ for the given $i_{q}$. Also the modulation pattern of the current commutation sectors depends on $\angle \underline{i}_{\alpha \beta}$ as can be seen. The magnetic saturation saliency modulation $\Delta \underline{z}^{\prime}{ }_{\text {PWM2 Sat }}$ has the expected shape. From these figures, it can be seen that $\triangle \underline{z}_{P W M 2}^{\prime}$ Sat is up to $10 \mathrm{~V} / \mathrm{A}$ and the saturation axis, where $\operatorname{Re}\left(\Delta \underline{z}^{\prime}{ }_{P W M 2}{ }_{L U T}\right)$ is minimum and $\operatorname{Im}\left(\Delta \underline{z}^{\prime}{ }_{P W M 2}{ }_{L U T}\right)$ is zero, is approximately at $\angle \underline{i}^{\prime}{ }_{P W M 2}-\angle \underline{i}=0^{\circ}{ }_{\text {ele. }}$. This indicates that the magnetic saturation axis is near the stator current vector.

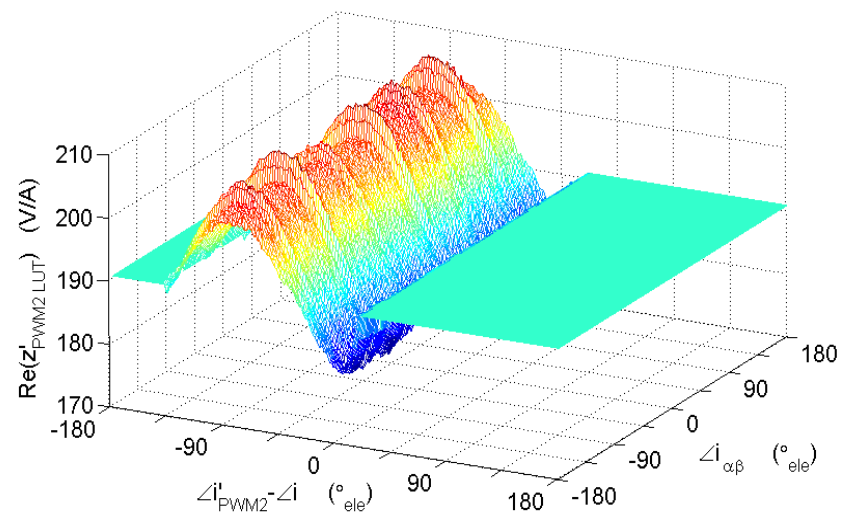

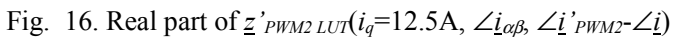

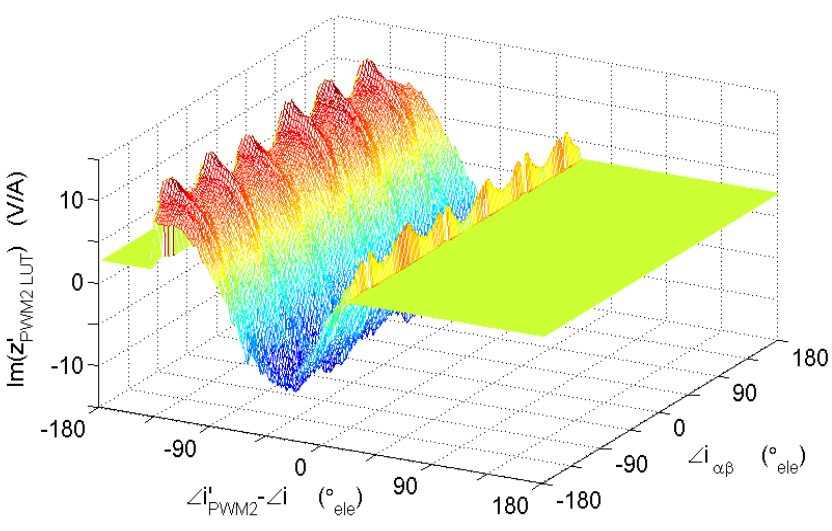

Fig. 17. Imaginary part of $\underline{z}^{\prime}{ }{ }_{W M 2}{ }_{L U T}\left(i_{q}=12.5 \mathrm{~A}, \angle \underline{i}_{\alpha \beta}, \angle \underline{i}^{\prime}{ }^{\prime}{ }_{W M 2}-\angle \underline{i}\right)$

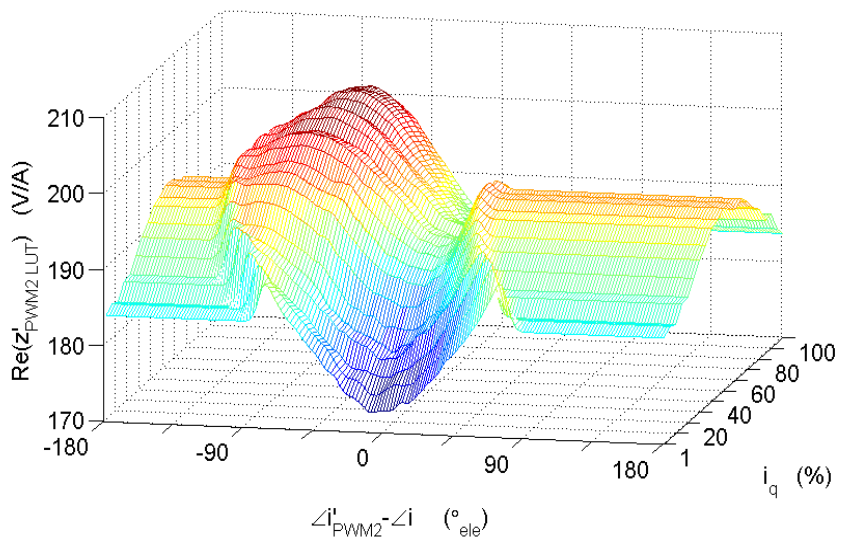

Fig. 18. Real part of $\underline{z}^{\prime}{ }_{\text {PWM2 } L U T}\left(i_{q}, \angle \underline{i}_{\alpha \beta}=0^{\circ}{ }_{\text {ele }}, \angle \underline{i}^{\prime}{ }_{P W M 2}-\angle \underline{i}\right)$

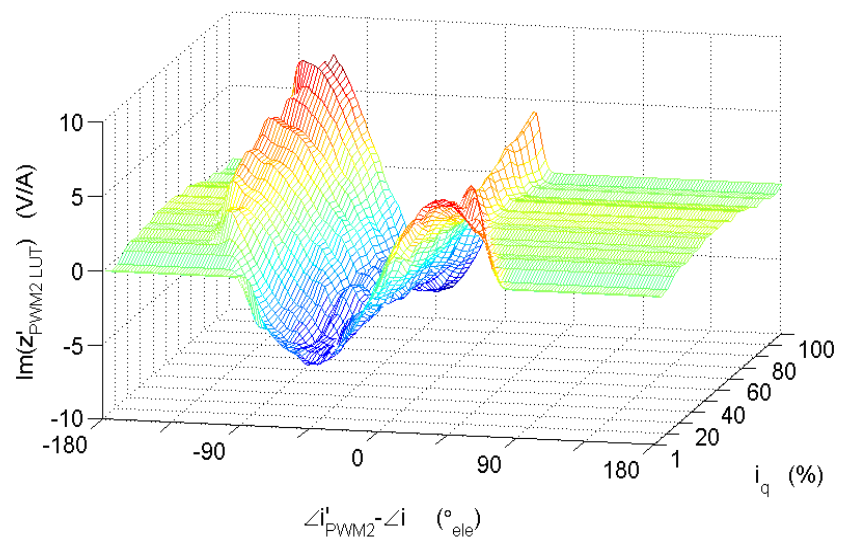

Fig. 19. Imaginary part of $\underline{z}^{\prime}{ }^{\prime}{ }_{W M 2}{ }_{L U T}\left(i_{q}, \angle \underline{i}_{\alpha \beta}=0^{\circ}{ }_{\text {ele }}, \angle \underline{i}_{P W M 2}-\angle \underline{i}\right)$

Figs. 18 and 19 show the equivalent impedance compensation values as function of $i_{q}$ and $\angle \underline{i}{ }^{\prime}{ }^{\prime}{ }_{W M 2}-\angle \underline{i}$. The $3 \mathrm{D}$ graphs shows the data for the fundamental stator current position $\angle \underline{i}_{\alpha \beta}=0^{\circ}$ ele. In Fig. 18 can be seen that the offset in the real part of $\underline{z}^{\prime}{ }_{P W M 2}$ also changes with $i_{q}$. Therefore it can be assumed that the offset $Z$ ' is also a function of the machine currents amplitude.

Dynamic disturbances were observed in the LUT decoupling. To reduce the likelihood of rotor bar skipping, phase locked loops (PLLs) are used in the sensorless rotor 
position estimator as shown in Fig. 20. One PLL (PLL1) is used to track and filter the measured $\Delta \underline{z}^{\prime}{ }_{P W M 2} R B$ modulation, which contains the rotor bar modulation signal $-\left(\theta_{R B}+2 \angle \underline{\prime}^{\prime}{ }_{P W M 2 \alpha \beta}\right)$. A second PLL (PLL2) is used to condition the final derived rotor bar position signal. The second PLL block is also used to obtain the mechanical position and a filtered speed estimate.

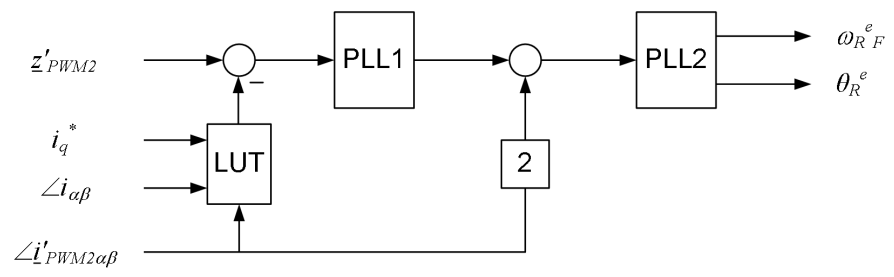

Fig. 20. Signal tracking PLL's in the sensorless algorithm

\section{Experimental Results}

Figs. 21 shows results when the sensorless induction motor drive is operating in sensorless current control mode under full load. The speed is controlled by the coupled DC machine. The reference speed of the load DC machine is set to zero and $53 \mathrm{rpm}$, which is approximately the full load slip frequency of the induction machine. It can be seen that the sensorless algorithm tracks the correct rotor position and mechanical and electical zero speed.
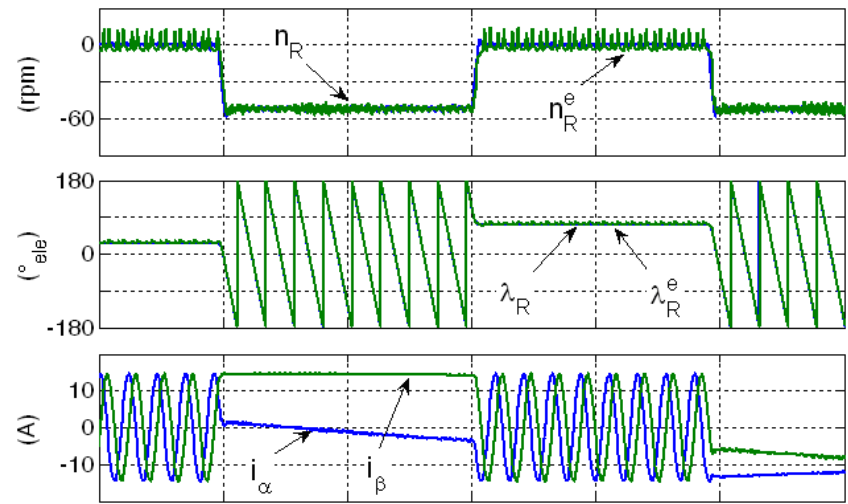

Fig. 21. PWM2 Harmonics Sensorless IM drive in Vector Current Control, Top: measured (blue) and estimated (green) mechanical speed $n_{R}$ and $n_{R}{ }^{e}$, Middle: measured mechanical rotor position $\lambda_{R}$ (blue) and estimated rotor position $\lambda_{R}{ }^{e}$ (green), Bottom: $i_{\alpha \beta}$ current components of the sensorless

\section{CONCLUSION}

The sensorless techniques reviewed in this paper have shown significant potential in the very low and zero speed regions. Compensation was required to overcome the disturbing effect of other saliencies originating from saturation and inverter non linearity effects. The move towards techniques injecting lower strength signals or no additional test signals have made the compensation crucial for the reliable operation of sensorless drives. The complexity of the necessary compensating signals might limit the attractiveness of non model based sensorless drives for industrial applications. The development of novel motor designs and auto commissioning compensation techniques will facilitate the implementation of the considered techniques allowing more widespread use in industry.

\section{REFERENCES}

[1] J. Cilia, G.M. Asher, K.J. Bradley and M. Sumner, "Sensorless Position Detection for Vector Controlled Induction Motor Drives using an Asymmetric Outer-Section Cage," IEEE Transactions on Industry Applications, Vol. 33 No. 5, Sep/Oct 1997, pp. 1162-1169.

[2] C. Spiteri Staines, G.M. Asher and K.J. Bradley, "A Periodic Burst Injection Method for Deriving Rotor Position in Saturated Cage-Salient Induction Motors without a Shaft Encoder," IEEE Transactions on Industry Applications, Vol. 35 No. 4, Jul/Aug 1999, pp. 851-858.

[3] M. Schrödl, "Sensorless Control of AC Machines at Low Speed and Standstill Based on the INFORM Method," IEEE IAS Annual Meeting, San Diego, USA, Oct. 1996, Vol. 1 pp. 270-277.

[4] J. Ha and S. Sul, "Sensorless Field Orientation Control of an Induction Machine by High Frequency Signal Injection," IEEE Transactions on Industry Applications, Vol. 35, No. 1, Jan/Feb 1999, pp. 45-51.

[5] K. Ide, I. Murokita, M. Sawanura, M. Ohto, Y. Nose, J. Ha and S. Sul, "Finite Element Analysis of Sensorless Induction Machine by High Frequency Voltage Injection," IPEC Tokyo 2000, Vol. 4, pp. 18421847.

[6] J. Holtz, "Sensorless Position Control of Induction Motors - An Emerging Technology," IEEE Transactions on Industrial Electronics, Vol. 45, No. 6, Dec. 1998, pp. 840-852.

[7] P.L. Jansen and R.D. Lorenz, "Transducerless Position and Velocity Estimation in Induction and Salient AC Machines," IEEE Transactions on Industry Applications, Vol.31, No.2, pp. 240-247, March/April 1995.

[8] P.L. Jansen and R.D. Lorenz, "Transducerless Field Orientation Concepts Employing Saturation Induced Saliencies in Induction Machines," IEEE IAS Annual Meeting, Vol. 1, 1995, pp. 174-181.

[9] J. Cilia, G.M. Asher and K.J. Bradley, "Sensorless Position Control for Induction Motor Drives using an Asymmetric Rotor and High Frequency Injection," Proceedings of the E.P.E. Conference, Norway, Vol. 4, September 1997, pp. 486-491.

[10] C. Spiteri Staines, J.Cilia and G.M.Asher, "Sensorless Position Estimation in Induction Machines," $9^{\text {th }}$ International Conf. On Power Electronics and Motion, EPE-PEMC 2000, Koscie, pp6.101-6.108.

[11] N. Teske, G. M. Asher, M. Sumner, and K. J. Bradley, "Encoderless position estimation for symmetric cage induction machines under loaded conditions," IEEE Transactions on Industrial Applications, no. 6, vol. 37, pp. 1793-1800, Nov/Dec. 2001.

[12] Ferrah, P.J. Hogen-Laing, K.J. Bradley, G.M. Asher and M.S. Woolfson, "The Effect of Rotor Design on Sensorless Speed Estimation using Rotor Slot Harmonics Identified by Adaptive Digital Filtering using the Maximum Likelihood Approach," IEEE IAS Annual Meeting, New Orleans, 1997, pp. 128-135.

[13] M.W. Degner and R.D. Lorenz, "Using multiple saliencies for the estimation of flux, position, and velocity in AC machines," IEEE Trans.Industry Applications, vol. 34, pp. 1097-1104, Sep/Oct 1998.

[14] M. Schrödl, "Sensorless Control of AC Machines," Fortschr.-Ber., VDI Reihe 21, Nr. 117, VDI-Verlag GmbH, Düsseldorf, 1992.

[15] F. Blaschke, J. van der Burgt and A. Vandenput, "Sensorless Direct Field Orientation at Zero Flux Frequency," IEEE IAS Annual Meeting, San Diego, Oct. 1996, Vol. 1, pp. 189-196.

[16] M.W. Degner and R.D. Lorenz, "Position Estimation in Induction Machines Utilizing Rotor Bar Slot Harmonics and Carrier-Frequency Signal Injection," IEEE Transactions on Industry Applications, May/June 2000, Vol. 36, No. 3, pp. 736-742.

[17] N. Teske, G.M. Asher, K.J. Bradley and M. Sumner, "Sensorless Position Estimation for symmetric Cage Induction Motor under Loaded Conditions," IEEE IAS Annual Meeting, Roma, Italy, Oct. 2000, Vol. 3 pp. 1835-1841.

[18] N. Teske, G.M. Asher, K.J. Bradley and M. Sumner, "Analysis and Suppression of Inverter Clamping Saliency in Sensorless Position Controlled Induction Machine Drives," IEEE IAS Annual Meeting, Chicago, USA, Sept./Oct. 2001, Vol. 4 pp. 2629-2636.

[19] C. Silva, G. M. Asher and M. Sumner, "Influence of Dead-time Compensation on Rotor Position Estimation in Surface Mounted PM 
Machines using HF Voltage Injection," Power Conversion Conference (PCC), Osaka, Japan, April 2002.

[20] F. Briz, A. Diez and M.W. Degner, "Dynamic Operation of CarrierSignal-Injection-Based Sensorless Direct Field-Oriented AC Drives," IEEE Transactions on Industry Applications, Sept./Oct. 2000, Vol. 36, No. 5, pp. 1360-1368.

[21] C. Caruana, G. M. Asher and J. Clare, "Sensorless Flux Position Estimation at Low and Zero Frequency by measuring Zero-Sequence Current in Delta Connected Cage Induction Machines", CD-ROM, IEEE IAS Annual Meeting, Salt Lake City, 2003.

[22] N.Teske, C.Spiteri Staines, J.Cilia and G.M.Asher, "Sensorless Position and Speed Estimation in Induction Machines", EPE-PEMC 2002, Croatia Sep. 2002, CD-ROM.

[23] J. Juliet, J.Holtz, "Sensorless Aquisition of the Rotor Position Angle for Induction Motors with Arbitrary Stator Windings", IEEE Transactions on Industrial Applications, Volume 41, Issue 6, Nov/Dec. 2005, pp: $1675-1682 .$.

[24] Spiteri Staines, C.; Caruana, C.; Asher, G.M.; Sumner, M., "Sensorless control of induction Machines at zero and low frequency using zero sequence currents" IEEE Transactions on Industrial Electronics, Volume 53, Issue 1, Feb. 2006, pp: 195-206.

[25] J.W. Choi and S.K. Sul, "Inverter Output Voltage Synthesis using Novel Dead Time Compensation," IEEE Transactions on Power Electronics.

[26] R. Raute, C. Caruana, J. Cilia, C. Spiteri Staines, M. Sumner and G. M. Asher, "Sensorless Control of Induction Machines at Low and Zero Speed Using PWM Harmonics for Rotor Bar Slotting Detection," IEEE Transactions on Industry Applications, vol. 46, no. 5, pp. 1989-1998, Sep./Oct. 2010.

[27] R. Raute, C. Caruana, J. Cilia, C. Spiteri Staines, M. Sumner and G. M. Asher, "Analysis and Compensation of Inverter Non-linearity Effect on a Sensorless PMSM Drive at Very Low and Zero Speed Operation," IEEE Transactions on Industrial Electronics, Vol. 57, No. 12, pp. $4065-$ 474, Dec. 2010.

[28] R. Raute, et al., "Operation of a Sensorless PMSM Drive Without Additional Test Signal Injection," in Proc. PEMD, York, UK, pp. 616620, 2-4 April 2008, 2008. 